\title{
Analysis of Ultra Sound Kidney Image Features for Image Retrieval by Gray Level Co-Occurrence Matrices
}

\author{
S. Manikandan, Senior Member, IACSIT, V. Rajamani, and N. Murugan
}

\begin{abstract}
Medical imaging is though expensive because of capital costs, is easy to perform because of its noninvasive nature. In order to provide better analysis and diagnosis, various features have been extracted from any images. In this paper many important features of the ultra sound kidney images have been extracted and analysis has been made for the proposed image retrieval from the image database. Quantitative establishment of use the features for detection of abnormalities in Ultra sound kidney images have been made. Here, we made an analysis that the texture has been used to discriminate among the various types of tissue in image applications. Various important features namely contrast, homogeneity, correlation, energy, autocorrelation, variance, co-variance, inertia, promenance, shade, dissimilarity, inverse difference moment (IDM), maximum probability and entropy have been extracted and analyzed for the application in connection of a image database for the image retrieval process.
\end{abstract}

Index Terms-Extraction, features, statistical test image retrieval, ultra sound kidney image.

\section{INTRODUCTION}

Visual features were classified into primitive features such as color or shape, logical features such as identity of objects shown and abstract features such as significance of scenes depicted [1]. Still, currently available systems only use primitive features unless manual annotation is coupled with the visual features [2]. Even systems using segments and local features such as Blob world are still far away from identifying objects reliably. No system offers interpretation of images or even medium level concepts as they can easily be captured with text [3]-[4].

This loss of information from an image to a representation by features is called the semantic gap [5].In earlier stages, features were calculated in the spatial domain, and the statistical nature of texture was taken into account in the procedure, which was based on the assumption that the texture information in an image I was contained in the overall or "average" spatial relationship which the gray tones in the image have to one another [6]. The classification of ultrasonic liver images by making use of some powerful texture features, including the spatial graylevel dependence matrices, Fourier power spectrum, the gray-level difference statistics, and the Laws' texture energy

Manuscript received August 8, 2012; revised November 9, 2012.

S. Manikandan is with the Departement of Computer Applications, R.M.D. Engineering College, Kavaraipettai, Chennai, Tamil nadu, India. (e-mail: smk76dgl@gmail.com).

V. Rajamani is with the Indra Ganesan College of Engineering, Trichy, Tamil nadu, India.

N. Murugan is with the P.S.N.A. College of Engineering and Technology, Dindigul, Tamil nadu, India. measures were studied [7]. The texture could be used to discriminate between various tissue types that were inaccessible to human perception and if so, then what were the most useful parameters were investigated by Mir et al [8]. A texture image analysis technique for characterizing and recognizing typical, diagnostically most important, vascular patterns relating to cervical lesions were described by $\mathrm{Ji}$ et al [9]. Five different texture feature extraction methods were most popularly used in image understanding. They showed that there was considerable performance variability between the various texture methods. Later on Sharma and Singh [10] found that co-occurrence matrices and Law's method perform better than other techniques. A method for three-dimensional (3-D) texture analysis of magnetic resonance imaging brain datasets was developed. This method was based on extended, multi sort cooccurrence matrices that combine intensity, gradient and anisotropy image features in a systematic and consistent way [11].

\section{Statistical Methods OF FeAtURE EXTRACTION}

The evaluation and development of new approaches for calculating texture have been a particular focus. Historically there have been two major approaches, i.e., structural and statistical approaches. The structural approach describes a texture by a sub pattern or primitive and spatial distribution of primitives, so called the placement rule. The primitives are also called texture elements. For instance, to consider the brick wall the primitive is a brick and the placement rule specifies the arrangement of bricks in the wall. The statistical approach does not presume in term of primitive but it draws on the general set of statistical tool. It is the most widely used and more generally applied method because of its high accuracy and less computation time.

Texture statistics is frequently classified into first-order, second-order and high order statistics. They are referring to the gray level distribution of pixel on an image. The gray scale is a black and white image at any given focus of pixel, typically there is a corresponding intensity on a range from 0 (black) to 255 (white). That means an image is composed of an array of pixels of varying intensity across the image, the intensity corresponding to the level of grayness from black (0) to white (255) at any particular point in the image.

\section{A. Gray-Level Co-Occurrence Matrices}

The gray-level co-occurrence matrix (GLCM), a frequency matrix, is a useful method for enhancing details and is used as an aid for interpretation of an image. The GLCM is a tabulation of how often different combinations of pixel brightness values (grey levels) occur in an image. The GLCM indicates the frequency of a pair of pixels that 
are at "exactly the same distance and direction of the displacement vector". From this principal, it uses to computes the relationships of pixel intensity to the intensity of its neighboring pixels which are based on hypothesis that the same gray level configuration is repeated in a texture and pixels that are close together tend to be more related than pixels that are far away from each other [12]-[13].

Graycomatrix creates the GLCM by calculating how often a pixel with gray-level (grayscale intensity) value $i$ occurs horizontally adjacent to a pixel with the value j. Each element $(i, j)$ in GLCM specifies the number of times that the pixel with value $i$ occurred horizontally adjacent to a pixel with value $j$. The co-occurrence probabilities provide a second-order method for generating texture features. These probabilities represent the conditional joint probabilities of all pair wise combinations of grey levels in the spatial window of interest given two parameters: inter pixel distance $(\delta)$ and orientation $(\theta)$. The probability measure can be defined as:

$$
\operatorname{Pr}(x)=\left\{C_{i j} \mid(\delta, \theta)\right\}
$$

where, $C_{i j}$ (the co-occurrence probability) between grey levels $i$ and $\mathrm{j}$ and it can be defined as

$$
C i j=\frac{p i j}{\sum_{i, j=1}^{G} P i j}
$$

where, $P_{i j}$ represents the number of occurrences of grey levels $i$ and $j$ within the given window, given a certain $(\delta, \theta)$ pair and $\mathrm{G}$ is the quantized number of grey levels.

The sum in the denominator represents the total number of grey level pairs $(i, j)$ within the window. Graycomatrix calculates the GLCM from a scaled version of the image. By default, if $I$ is a binary image, graycomatrix scales the image to two gray-levels. If $I$ is an intensity image, graycomatrix scales the image to eight gray-levels

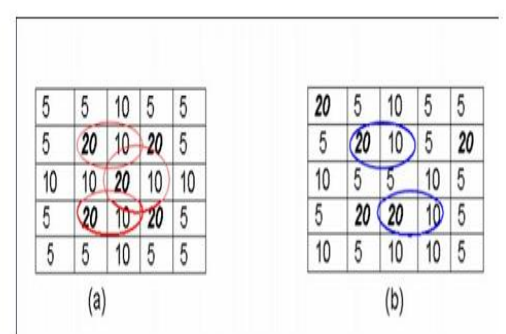

Fig. 1. Matrix of an image for calculating GLCM

If $\mathrm{h}=(0,1)$, i.e., one step in the horizontal direction, then c (GLCM) will be

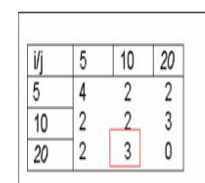

(a)

Fig. 2. GLCM of the Matrix
The position of each element in the matrix indicates which pixel values are being compared (Fig. 1.). The value at row $i$ and column $\mathrm{j}$ gives the number of times that a pixel with the value $j$ was to the immediate right of a pixel with the value $i$. Hence, the value 3 in the 2 nd column, 3 rd row of Fig. 2. indicates that a pixel value of 10 was to the right of a pixel with the value 20 counted 3 times. Meanwhile, the value 2 in the same position of GLCM from Fig. 2. means a pixel value of 10 was to the right of a pixel with the value 20 counted 2 times.

GLCM texture considers the relation between two pixels at a time, called the reference and the neighbor pixel. In the illustration, the neighbor pixel is chosen to be the one to the east (right) of each reference pixel. This can also be expressed as a $(1,0)$ relation: 1 pixel in the $x$ direct ion, 0 pixels in the $y$ direct ion. Each pixel within the window becomes the reference pixel in turn, starting in the upper left corner and proceeding to the lower right. Pixels along the right edge have no right hand neighbor, so they are not used for this count.

The top left cell is filled with the number of times the combination 0,0 occurs, i.e. how many times within the image area a pixel with grey level 0 (neighbor pixel) falls to the right of another pixel with grey level 0 (reference pixel). The result of a texture calculation is a single number representing the entire window. This number is put in the place of the centre pixel of the window, then the window is moved one pixel and the process is repeated of calculating a new GLCM and a new texture measure. In this way an entire image is built up of texture values.

\section{B. Determining the Gray Level Co Occurrence Matrix}

The gray level co occurrence matrix of the given images is calculated using the relation

glcm = graycomatrix (I) creates a gray-level cooccurrence matrix (GLCM) from image I.

The matrix has been calculated for all the images and for all the four directions that is, 0, 45, 90 and 135 .

Graycomatrix creates the GLCM by calculating how often a pixel with gray-level (grayscale intensity) value $i$ occurs horizontally adjacent to a pixel with the value $j$. Each element $(i, j)$ in glcm specifies the number of times that the pixel with value $i$ occurred horizontally adjacent to a pixel with value $j$. Due to the intensive nature of computations involved, only the distances $d=1$ with angles $\theta=0^{\circ}, 45^{\circ}$, $90^{\circ}$ and $135^{\circ}$ are considered.

glcm = gray comatrix $(\mathrm{I}$, param 1, val1, param 2, val $2, \ldots)$

returns one or more gray level co-occurrence matrices, depending on the values of the optional parameter/value pairs. The SYNTAX used for calculating GLCM of the images was:

glcm = graycomatrix $\left(\mathrm{I},{ }^{\prime} \quad\right.$ NUMLEVELS', 8, 'G',[],'Offset',[1 0]);

where, $I$ is the image.

Here, NUMLEVELS indicate the number of gray-levels to use when scaling the grayscale values in $I, 8$ is the number of gray levels. $G$ refers to Gray Limits that specifies how the grayscale values in I are linearly scaled into gray levels. We set the gray limits to [ ], where graycomatrix uses the minimum and maximum grayscale values in the image as limits [min (I (:)) $\max (\mathrm{I}(:))]$. 
The offset value is used to determine the distance and direction of pixel neighbor. [0 1] is the default value, that is, $0^{\circ}$ direction in which the relation between the gray level value of pixel of interest is found out relative to its next right neighbor. We have used four different directions to calculate the values of GLCM, that is, $0^{\circ}, 45^{\circ}, 90^{\circ}$ and $135^{\circ}$.

\section{RESULTS AND DISCUSSIONS}

The various texture parameters have been extracted for the ultrasound scan images of Kidney. Normal and abnormal Kidney ultrasound scan images have been taken and their textural parameters like contrast, homogeneity, correlation, energy, autocorrelation, variance, co-variance, inertia, promenance, shade, dissimilarity, inverse difference moment (IDM), maximum probability and entropy have been calculated.

TABLE I: RANGES OF FEATURE VALUES FOR DifFERENT CASES OF ULTRA

\begin{tabular}{|c|c|c|c|c|c|}
\hline S.No & $\begin{array}{c}\text { Feature } \\
\text { Value }\end{array}$ & $0^{0}$ & $45^{0}$ & $90^{\circ}$ & $135^{0}$ \\
\hline 1 & $\begin{array}{c}\text { Auto } \\
\text { correlation }\end{array}$ & $\begin{array}{c}6 . .345689 \\
- \\
9.958220\end{array}$ & $\begin{array}{c}6.338739 \\
- \\
9.954582\end{array}$ & $\begin{array}{c}6.327576 \\
- \\
9.953482\end{array}$ & $\begin{array}{c}6.344380 \\
- \\
9.974361\end{array}$ \\
\hline 2 & Contrast & $\begin{array}{c}0.077347 \\
- \\
0.154734\end{array}$ & $\begin{array}{c}0.146003 \\
- \\
0.312439\end{array}$ & $\begin{array}{c}0.130819 \\
- \\
0.254152\end{array}$ & $\begin{array}{c}0.142575 \\
- \\
0.272881\end{array}$ \\
\hline 3 & Promenance & $\begin{array}{c}4.625687 \\
- \\
100.2154\end{array}$ & $\begin{array}{c}3.822712 \\
- \\
95.71034\end{array}$ & $\begin{array}{r}3.915926 \\
-97.5733\end{array}$ & $\begin{array}{c}3.742209 \\
- \\
97.25427\end{array}$ \\
\hline 4 & Shade & $\begin{array}{c}-7.11241 \\
- \\
4.445509\end{array}$ & $\begin{array}{c}-7.39616 \\
- \\
3.723864\end{array}$ & $\begin{array}{c}-7.2515 \\
- \\
3.994704\end{array}$ & $\begin{array}{c}-7.34049 \\
- \\
4.047879\end{array}$ \\
\hline 5 & Dissimilarity & $\begin{array}{c}0.070937 \\
- \\
0.138464\end{array}$ & $\begin{array}{c}0.144024 \\
- \\
0.253844\end{array}$ & $\begin{array}{c}0.113343 \\
- \\
0.205277\end{array}$ & $\begin{array}{c}0.114286 \\
- \\
0.216229\end{array}$ \\
\hline 6 & Energy & $\begin{array}{c}0.225704 \\
- \\
0.541698\end{array}$ & $\begin{array}{c}0.191454 \\
- \\
0.495981\end{array}$ & $\begin{array}{c}0.202213 \\
- \\
0.506378\end{array}$ & $\begin{array}{c}0.203142 \\
- \\
0.499886\end{array}$ \\
\hline 7 & Entropy & $\begin{array}{r}1.024695 \\
-.767409\end{array}$ & $\begin{array}{c}1.170822 \\
- \\
1.972349 \\
\end{array}$ & $\begin{array}{c}1.142915 \\
- \\
1.910173 \\
\end{array}$ & $\begin{array}{c}1.164695 \\
- \\
1.905743 \\
\end{array}$ \\
\hline 8 & Homogeneity & $\begin{array}{l}0.933133 \\
-1.51213\end{array}$ & $\begin{array}{c}0.879131 \\
- \\
1.656119\end{array}$ & $\begin{array}{c}0.897746 \\
- \\
1.614562\end{array}$ & $\begin{array}{l}0.8932- \\
1.636517\end{array}$ \\
\hline 9 & $\begin{array}{l}\text { Maximum } \\
\text { probability }\end{array}$ & $\begin{array}{c}0.306803 \\
- \\
0.948411\end{array}$ & $\begin{array}{c}0.29549 \\
- \\
0.911292\end{array}$ & $\begin{array}{c}0.298789 \\
- \\
0.923868\end{array}$ & $\begin{array}{c}0.295404 \\
- \\
0.917404\end{array}$ \\
\hline 10 & Variance & $\begin{array}{c}5.636699 \\
- \\
9.947342 \\
\end{array}$ & $\begin{array}{c}5.678375 \\
- \\
10.02279\end{array}$ & $\begin{array}{c}5.657162 \\
-9.9921\end{array}$ & $\begin{array}{c}5.678375 \\
- \\
10.02151 \\
\end{array}$ \\
\hline 11 & Co-variance & $\begin{array}{c}0.219729 \\
- \\
1.824811\end{array}$ & $\begin{array}{c}0.181068 \\
- \\
1.733149\end{array}$ & $\begin{array}{c}0.18892 \\
- \\
1.767575\end{array}$ & $\begin{array}{c}0.182788 \\
- \\
1.752929\end{array}$ \\
\hline 12 & Correlation & $\begin{array}{c}0.850342 \\
- \\
0.971895 \\
\end{array}$ & $\begin{array}{c}0.712673 \\
- \\
0.937107\end{array}$ & $\begin{array}{c}0.74282 \\
- \\
0.939662 \\
\end{array}$ & $\begin{array}{c}0.719437 \\
- \\
0.932887\end{array}$ \\
\hline 13 & $\begin{array}{c}\text { Inverse } \\
\text { difference } \\
\text { moment }\end{array}$ & $\begin{array}{c}0.932395 \\
- \\
0.965778\end{array}$ & $\begin{array}{c}0.878402 \\
- \\
0.933055\end{array}$ & $\begin{array}{c}0.897639 \\
- \\
0.947759\end{array}$ & $\begin{array}{c}0.893086 \\
- \\
0.947126\end{array}$ \\
\hline 14 & Inertia & $\begin{array}{c}0.077347 \\
- \\
0.154734\end{array}$ & $\begin{array}{c}0.146003 \\
- \\
0.312439\end{array}$ & $\begin{array}{c}0.130819 \\
- \\
0.254152\end{array}$ & $\begin{array}{c}0.142575 \\
- \\
0.272881\end{array}$ \\
\hline
\end{tabular}

In the above Table, $V_{3}, V_{4}, V_{5}$ and $V_{6}$ refers the angles $0^{0}$, $45^{\circ}, 90^{\circ}$ and $135^{\circ}$ respectively. The statistical $\mathrm{T}$ test results shows that $\mathrm{t}$ value for an angle $0^{0}$ is $1.452, \mathrm{t}$ value for an angle $45^{\circ}$ is $1.471, \mathrm{t}$ value for an angle $90^{\circ}$ is 1.467 and $\mathrm{t}$ value for an angle $135^{\circ}$ is 1.4688 . All the $t$ values are lies between 1.452 and 1.471 . Here the minimum value occurs at an angle of $0^{0}$ and the maximum value occurs at an angle of $45^{\circ}$. For other angles the values are in between these values. Also the minimum standard error mean value occurs at an angle of $45^{\circ}$ and the maximum standard error mean value is at an angle of $0^{\circ}$. Hence, $0^{\circ}$ angle and $45^{\circ}$ angle values has been considered for comparison of features for image retrieval process.

TABLE II: STATISTICAL T TEST FOR ANALYSIS OF VARIOUS EXTRACTED FEATURES
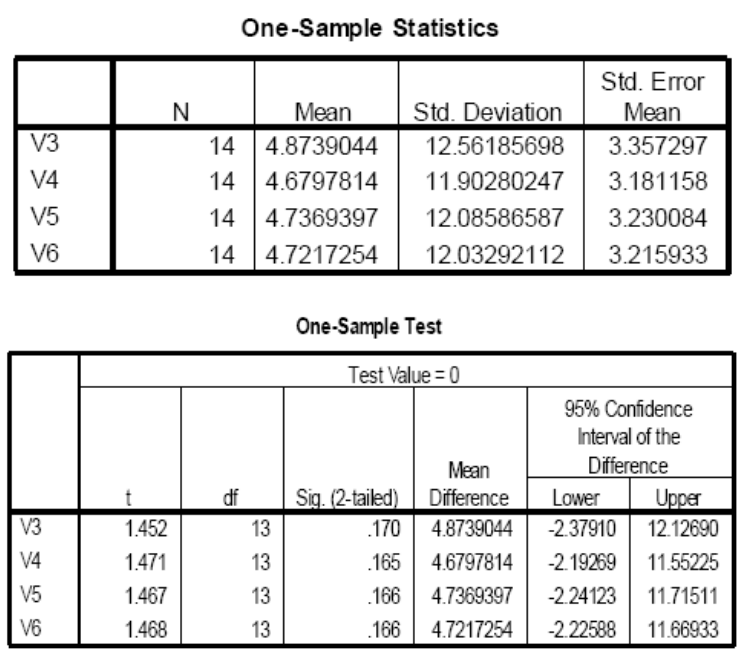

\section{CONCLUSION AND FUTURE WORK}

Various important features of an Ultra Sound Kidney images have been extracted and analyzed using gray level co occurrence matrices. $\mathrm{T}$ test has also been performed for the extracted features for the further application in image comparison, image retrieval from the data base for diagnostic purpose. It is also found from the $T$ test that the feature value in $0^{\circ}$ angle and $45^{\circ}$ angle are considered for further calculations of image retrieval. It is seen that the database with this parameter will be sufficient for comparative studies and retrieval while diagnosing. Only Ultra Sound images of kidney are studied in this work. Images of other body parts can be taken to see if the same results also apply to them or not. In addition, other images like MRI, CT Scan, X ray images etc. can also be taken and effects of various parameters can be studied on them.

\section{REFERENCES}

[1] J. P. Eakins and M. E. Graham, content-based image retrieval, Tech Rep. JTAP-039, JISC Technology Application Program, Newcastle upon Tyne 2000

[2] T. Pfund and S. M. Maillet, Dynamic multimedia annotation tool, in: G. Beretta, R. Schettini (Eds.), Internet Imaging III, vol. 4672 of SPIE Proceedings, San Jose, California, USA, pp. 216-224, 2002 (SPIE Photonics West Conference).

[3] C. Carson, M. Thomas, S. Belongie, J. M. Hellerstein, and J. Malik, Blobworld, A system for region-based image indexing and retrieval, in: D. P. Huijsmans, A. W. M. Smeulders (Eds.), presented at Third International Conference On Visual Information Systems (VISUAL 99), no. 1614 in Lecture Notes in Computer Science, Springer-Verlag, Amsterdam, The Netherlands, pp. 509-516, 1999.

[4] S. Belongie, C. Carson, H. Greenspan, and J. Malik, "Color and texture-based image segmentation using EM and its application to content $\{$ based image retrieval," in Proceedings of the International Conference on Computer Vision, Bombay, India, pp. 675-682, 1998. 
[5] A. W. M. Smeulders, M. Worring, S. Santini, A. Gupta, and R. Jain, "Content-based image retrieval at the end of the early years," IEEE Transactions on Pattern Analysis and Machine Intelligence, vol. 22, no. 12 , pp. 1349-1380, 2000.

[6] M. Haralick, K. Robert, K. Shanmugam, and Dinstein, "Textural Features for Image Classification," IEEE Transactions on Systems, Man and Cybernetics, vol. 6, no. 3, pp. 610 - 621, 1993.

[7] W. Chung-Ming, C. Yung-Chang, and H. Kai-Sheng, "Texture features for classification of ultrasonic liver images," Medical Imaging, IEEE Transactions on vol. 2, no. 11, pp. 141 - 152, 1992.

[8] A. H. Mir, M. Hanmandlu, and S. N. Tandon, "Texture analysis of CT images," IEEE Eng. Medical Biology Magazine, no. 14, pp. 781 786, 1995.

[9] Q. Ji, J. Engel, and E. Craine, "Texture analysis for classification of cervix lesions," IEEE Transactions on Medical Imaging, vol. 11, no. 19 , pp. $1144-1149,2000$

[10] M. Sharma and S. Singh, "Evaluation of texture methods for image analysis," in Proc. of Intelligent Information Systems Conference, The Seventh Australian and New Zealand, pp. 117 - 121, 2001.

[11] V. A. Kovalev, F. Kruggel, H. J. Gertz, and D. Y. V. Cramon, "Three-dimensional texture analysis of MRI brain datasets," IEEE Transactions on Medical Imaging, vol. 5, no. 20, pp. 424 - 433, 2001.

[12] R. Haralick, "Statistical and Structural Approaches to Texture," in Proceedings of IEEE 67, pp. 786 - 804, 1999.

[13] J. S. DaPonte, J. Gelber, and M. D. Fox, "Effect of co occurrence displacement vector on quantization of ultrasonic image texture Bioengineering Conference," in Proceedings of the 1988 Fourteenth Annual Northeast, pp. 298 - 300, 1988.

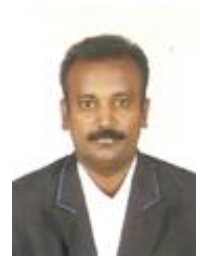

S. Manikanan was born in Tamilnadu, India in 1976 He received M.C.A., from Bharathidasan University, Trichy, India in the year 1999 and M.Phil. (Computer Science) from Manonmaniam Sundaranar University, Tirunelveli, India in the year 2003. He received Ph.D. in Computer Science from Anna University Chennai, Inida in the year 2009. His area of interest includes image processing, networks and data mining. He is having 13 years of teaching experience in the department of Computer Science. He published 8 research papers in international journals and presented 25 papers in national and international conferences. He has written a book on Software Project Management. He is the member of ISTE and senior member of IACSIT.

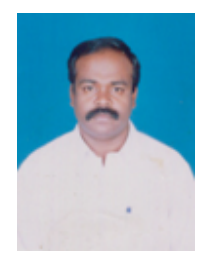

V. Rajamani was born in Tamilnadu, India in 1968 $\mathrm{He}$ received B.E in Electronics and Communication Engineering at Madurai Kamaraj University, Madurai, Tamilnadu, India, in the year 1990, M.E in Applied Electronics at Bharathiyar University, Coimbatore, Tamilnadu, India in the year 1995 and Ph.D. degree in Optical Communication from Institute of Technology, Banaras, Varanasi, in 1999. He started his academic carrier in the year 1991 as Lecturer. Currently he is working as a Principal in Indra Ganesan College of Engineering, Trichy, TN, India. Under his guidance 10 research scholars were awarded doctoral degrees. In addition to this, he has guided more than 10 PG thesis and 10 UG thesis work. He published more than 102 papers in referred national and international journals and conferences. His area of interest includes Device Modelling, VLSI, Image Processing and Optical Communication. He is the life member of ISTE, New Delhi, India, and member in IEEE.

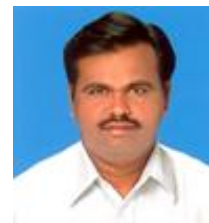

N. Murugan was born in Tamilnadu, India in 1968 He received M.B.A., from Madurai Kamaraj University, Madurai, India in the year 2001 and received Ph.D. in Management Science from Gandhigram Rural University Dindigul, Inida in the year 2007. His area of interest includes management science and database management systems. He is having 18 years of teaching experience in the department of Management Science. He published 5 research papers in international journals and presented 30 papers in national and international conferences. He is the member of ISTE. 